Onkologie 1992;15:173

\title{
Impressum, Vol. 15, No. 3, 1992
}

Offizielles Organ der Deutschen Gesellschaft für Hämatologie und Onkologie, der Osterreichischen Gesellschaft für Hämatologie und Onkologie, der Osterreichischen Krebsgesellschaft - Krebsliga unter Fortführung der «Osterreichischen Zeitung für Onkologie» Schriftleitung

H. Huber, Innsbruck W. Queißer, Mannheim Fachschriftleitung

W. E. Berdel, Berlin E. Dühmke, Göttingen N. Jaeger, Hildesheim M. Kaufmann, Heidelberg P. Schlag, Heidelberg

Wissenschaftlicher Beirat

W. E. Berdel, Berlin V. Diehl, Köln

C. Dittrich, Wien

P. Drings, Heidelberg

E. Dühmke, Göttingen

H. H. Fiebig, Freiburg

A. Gläser, Halle

R. Hartenstein, München

K. Havemann, Marburg

K. P. Hellriegel, Berlin

R. Herrmann, Basel

H. W. von Heyden, Einbeck

D. Hoelzer, Frankfurt/M.

J. H. Holzner, Wien

H. Huber, Innsbruck H. J. Illiger, Oldenburg N. Jaeger, Hildesheim R. Jakesz, Wien M.

Kaufmann, Heidelberg

U. R. Kleeberg, Hamburg

B. Kornhuber, Frankfurt/M.

H. Löffler, Kiel

H. Ludwig, Wien

U. Mohr, Hannover

K. Munk, Heidelberg

G. A. Nagel, Vitikon-Zürich

A. Pfleiderer, Freiburg

F. Porzsolt, Ulm

K. Possinger, München

W Queißer, Mannheim

P. Schlag, Heidelberg

H.-J. Schmoll, Hannover

M. Schroder, Kassel

S. Seeber, Essen 
W. Vahlensieck, Bonn

H. W. Waclawiczek, Salzburg

M. Wannenmacher, Heidelberg

H. J. Weh, Hamburg

W. Wilmanns, München

Die Zeitschrift erscheint zweimonatlich; pro Jahr erscheint 1 Band zu je 6 Heften.

Bezugspreis für Jahrgang 15, 1992, DM 159-/öS 1113,-/SFr 124,-. 1 Einzelheft kostet DM 30,-/öS 210-/SFr 23-, einschließlich MwSt., zuzüglich Postgebühren.

Der Abonnementpreis ist im voraus zahlbar. Das Abonnement der Zeitschrift läuft weiter, wenn es nicht spätestens 4 Wochen vor Abschluß eines Bandes abbestellt wird.

Abonnementbestellungen können bei jeder Buchhandlung oder direkt beim Verlag aufgegeben werden:

Bundesrepublik Deutschland/Österreich: S. Karger GmbH, Postfach 1724, W-8034 Germering/München, Telefon (089) 843035, Telex 524865 D, Telefax

84180 83, Postgiro München 40080-807

Schweiz: S. Karger AG, Allschwilerstr. 10, Postfach, CH-4009 Basel, Telefon

(061) 3 061111, Telex 62652 CH, Telefax (061) 3061234

Anzeigen

S. Karger Verlag für Medizin und Naturwissenschaften GmbH, Postfach 1724, W-8034 Germering/München, Telefon (089) 843035.

Gültig ist die Preisliste Nr. 6 vom 1.10.1990.

Für den Inhalt außerhalb des redaktionellen Teiles (insbesondere Anzeigen, Industrieinformationen, Pressezitate und Kongreßinformationen) übernehmen

Schriftleitung, Beirat und Verlag keine Gewähr.

Eine Markenbezeichnung kann warenzeichenrechtlich geschützt sein, auch wenn bei ihrer Verwendung in dieser Zeitschrift das Zeichen ${ }^{\circledR}$ oder ein anderer Hinweis auf etwa bestehende Schutzrechte fehlen sollte. Für Satzfehler, insbesondere bei Dosierungsangaben, wird keine Gewähr übernommen.

Die Zeitschrift sowie alle in ihr enthaltenen einzelnen Beiträge und Abbildungen sind urheberrechtlich geschützt. Jede Verwertung, die nicht ausdrücklich vom Ur-heberrechtsgesetz zugelassen ist, bedarf der vorherigen Zustimmung des Verlags. Das gilt insbesondere für Vervielfältigungen, Bearbeitungen, Übersetzungen, Mi-kroverfilmungen und die Einspeicherung und Verarbeitung in elektronischen Sy-stemen. Fotokopien dürfen nur für den persönlichen Gebrauch als Einzelkopien hergestellt werden. Jede im Bereich eines gewerblichen Unternehmens zulässig hergestellte oder benutzte Kopie dient gewerblichen Zwecken gem. § 54(2) UrhG und verpflichtet zur Gebührenzahlung an die Verwertungsgesellschaft WORT, Abt. VG Wissenschaft, Goethestraße 49, W-8000 München 2.

(C) Copyright 1992 by S. Karger

Verlag für Medizin und Naturwissenschaften GmbH

Postfach 1724

W-8034 Germering (BRD)

Presserechtlich verantwortlich: Manfred R. Just 
Verlagsleitung: Manfred R. Just

Redaktionsassistenz: Anne Schieber

Anzeigenverkauf: Marlene Scholz

Anzeigenverwaltung: Eva M. Lindenau

Herstellung: Horst H. Bruch

Vertrieb: Gabriela Taube

Satz und Druck: Walter Biering GmbH

Grafischer Betrieb

Freisinger Landstraße 21

W-8000 München 45 (BRD)

KAIUiER 